\title{
LA CONFIGURACIÓN DEL PAISAJE ANDINO EN EL DISCURSO POÉTICO DEL VANGUARDISMO PUNEÑO
}

\author{
THE CONFIGURATION OF THE ANDEAN LANDSCAPE \\ IN THE POETIC DISCOURSE OF PUNO VANGUARDISM
}

\section{A CONFIGURAÇÃO DA PAISAGEM ANDINA NO DISCURSO POÉTICO DO VANGUARDISMO PUNO}

Yoselin Quispe Mendivil ${ }^{1}$

Universidad Nacional Mayor de San Marcos yoselin.quispe@unmsm.edu.pe

ORCID: 0000-0001-9973-9240

Recibido: $12 / 02 / 21$

Aceptado: 5/03/21

1 Licenciada en Lingüística por la UNMSM, egresada de la Maestría en Literatura con mención en Literatura Peruana y Latinoamericana y miembro del Grupo de Investigación Estudios de Lingüística y de Lingüística Interdisciplinaria (ELDLI). Además, ha publicado los siguientes artículos: "Estudio lexicográfico de los eufemismos sexuales novedosos en las novelas de Mario Vargas Llosa" (2020) y "La configuración de la muerte en el discurso poético de Javier Heraud" (2021). 


\title{
Resumen
}

En el presente trabajo de investigación se tiene como objetivo comparar las similitudes y diferencias respecto a la configuración del paisaje andino en el poema "balsas matinales", de Ande (1926), de Alejandro Peralta frente a "Yaraví Titicaca", de Altipampa (1933), de Emilio Vásquez. Este estudio postula que en el discurso poético de Peralta se reivindica de forma más marcada la importancia de las actividades cotidianas del hombre andino como la pesca, el pastoreo, la agricultura, la ganadería, el andinismo y las fiestas patronales andinas. Por otro lado, en el discurso poético de Vázquez se utilizan, en mayor medida, las categorías pampa y lago para indicar la influencia de estos paisajes en la subjetividad del hombre andino. Para realizar el estudio, se utilizan los marcos teóricos de la Retórica y la Literatura comparada y, por ello, se siguen los lineamientos de Arduini (2000) y Steiner (1978-1992), respectivamente.

Palabras claves: paisaje andino, pampa, lago, actividades cotidianas, subjetividad poética.

\begin{abstract}
The objective of this research work is to compare the similarities and differences with respect to the configuration of the Andean landscape in the poem "balsas matinales", in Ande (1926), by Alejandro Peralta versus "Yaraví Titicaca", in Altipampa (1933) by Emilio Vásquez. This study postulates that in Peralta's poetic discourse it vindicates in a more marked way the importance of the daily activities of the andean man such as fishing, pastoralism, agriculture, cattle ranching, andeanism and andean patronal saint festivals. On the other hand, in Vázquez's poetic discourse, the pampa and lago categories are used to a greater extent to indicate the influence of these landscapes on the subjectivity of the Andean man. To carry out the study are used the theoretical frameworks of Rhetoric and Comparative literature and, therefore, are followed the guidelines of Arduini (2000) and Steiner (1978-1992), respectively.
\end{abstract}

Keyboards: andean landscape; pampa; lago; daily activities; poetic subjectivity.

\section{Resumo}

O objetivo deste trabalho de pesquisa é comparar as semelhanças e diferenças a respeito da configuração da paisagem andina no poema "balsas matinales", de Ande (1926), de Alejandro Peralta, versus "Yaraví Titicaca”, de Altipampa (1933) de Emilio Vásquez. Este estudo postula 
que no discurso poético de Peralta reivindica se, de maneira mais marcante, a importância das atividades cotidianas do homem andino, como a pesca, a pastorícia, a agricultura, a pecuária, o andeanismo e as festividades andinas. Por outro lado, no discurso poético de Vázquez, as categorias pampa e lago são utilizadas em maior medida para indicar a influência dessas paisagens na subjetividade do homem andino. Para a realização do estudo, são utilizados os referenciais teóricos da Retórica e da Literatura comparada e, para tanto, são seguidas as orientações de Arduini (2000) e Steiner (1978-1992), respectivamente.

Palabras chave: paisagem andina; pampa; lago; atividades cotidianas; subjetividade poética.

\section{Introducción}

El presente estudio constituye la comparación del discurso poético de Ande (1926), de Alejandro Peralta frente a la concepción expresada por Emilio Vásquez en Altipampa (1933) sobre el tópico de la configuración del paisaje andino puneño. Asimismo, este trabajo de investigación busca considerar las propuestas de dichos poetas en su faz interpeladora; esto es, asumir que la poesía es actualizada en la lectura del poema hecha por el lector, el cual está inscrito en un tiempo determinado y es movido por el hacer poético, persuadido por él. En otras palabras, se busca mostrar el matiz retórico en la poesía vanguardista puneña para indicar la influencia del paisaje andino en la subjetividad del hombre andino, así como para reivindicar la importancia de las actividades cotidianas de los collavinos.

En el presente trabajo de investigación se tiene como objetivo sostener la afirmación anterior a partir del análisis de dos textos poéticos que tienen como eje articulatorio la configuración del paisaje andino. De tal modo, se analiza un poema de Alejandro Peralta, el cual será confrontado con un poema de Emilio Vázquez. Se confronta "balsas matinales", de Alejandro Peralta frente a "Yaraví Titicaca", de Emilio Vásquez. La exégesis comprende el análisis de la dispositio, la elocutio, la 
interlectio y la inventio de los textos. La comparación entre las unidades de análisis permite el diálogo entre los puntos de vista de ambos autores y, además, permite visibilizar cómo en la poesía vanguardista puneña, el paisaje andino se resuelve en una presencia viva que se representa de diferentes maneras ante la presencia de lo humano.

\section{Marco teórico}

\subsection{Paisaje andino}

El paisaje andino "implica una cierta manera de contemplar la naturaleza, además que puede incluir objetos culturales, no así la naturaleza. Así, el término paisaje representa un recorte o una imagen fija, un punto de vista respecto a la naturaleza que en su unidad aparece como un resultado cuyo nacimiento y razón de ser tienen que ser reconstruidos" (Martina Kopf, 2011, p. 104).

\subsection{Hecho, texto y campo retórico}

Tomás Albaladejo (1991, p. 43) establece una diferenciación entre el hecho retórico y el texto retórico. El primero, está formado por el orador o productor, el destinatario o receptor, el texto retórico, el referente de este y el contexto en el que se produce. El segundo, pertenece al primero y es imprescindible para la existencia de este. Ambos, afirma el autor, "forman una construcción en la que las relaciones semánticas pragmáticas, sintácticas y pragmáticas están solidariamente establecidas”. Así, la sucesión de operaciones constituyentes del hecho retórico, es decir, la interlectio, inventio, dispositio, elocutio, memoria y actio permiten dar cuenta de que en la organización del texto retórico interviene también la profundización sobre la circunstancia específica en el que este se origina: todo ello con el fin de agenciar al orador del discurso de la competencia necesaria para lograr 
el propósito de persuadir del auditorio de ponerse a favor de la causa que defiende.

\subsection{Los campos figurativos}

Con respecto a la clasificación de los campos figurativos, Arduini (2000, p. 45) distingue seis campos: metáfora, metonimia, sinécdoque, antítesis, repetición y elipsis. La propuesta de Arduini se destaca de las investigaciones anteriores sobre el campo retórico, ya que añade a la configuración de las figuras retóricas la representación de un pensamiento o una verdad del mundo y no solo constituye un mero listado o taxonomía de las figuras retóricas.

\subsection{Literatura comparada}

Para Steiner (1978-1992, p. 124), la literatura comparada constituye el primer paso hacia la búsqueda del conocimiento, pues se trata de la constitución de teorías que busquen explicar el fenómeno literario. Según Steiner, "El proceso semántico es un proceso de diferenciación. Leer es comparar”. En relación a lo señalado, Asensi (2010, p. 83) sostiene que "toda descripción de un texto es necesariamente comparada, que en rigor no puede haber teoría, ejercicio crítico o análisis del discurso sin los términos que estamos describiendo". Para Asensi (ibídem, 84), la literatura comparada se relaciona con los estudios teóricos, asimismo, sin su aplicación se produciría una inadecuada sistematización de los estudios literarios.

\subsection{Modalidad intraliteraria}

Siguiendo la clasificación de Asensi (ibídem), el presente trabajo de investigación se inscribe dentro de la modalidad intraliteraria, esto es, la relación de un texto literario, Ande (1926), de Alejandro Peralta, con otro texto literario perteneciente a una misma lengua, Altipampa (1933), de Emilio Vásquez. 


\section{Metodologia}

Para analizar la configuración del paisaje andino, se escogieron los siguientes dos poemas: "balsas matinales", de Ande (1926), de Alejandro Peralta y "Yaraví Titicaca", de Altipampa (1933), de Emilio Vásquez porque en estos se presenta el foco de estudio de forma marcada. Estos poemarios se encuentran disponibles en la Biblioteca Central Pedro Zulen de la Universidad Nacional Mayor de San Marcos. Asimismo, para realizar el estudio, se decidió utilizar los marcos teóricos de la Retórica y la Literatura Comparada propuestos por Arduini (2000) y Steiner (19781992), respectivamente, ya que el objetivo del presente estudio es contrastar los poemarios emblemáticos de la vanguardia puneña pertenecientes a Alejandro Peralta y Emilio Vásquez. En el trabajo de investigación se tiene como fin determinar la cosmovisión del sujeto poético, a partir de la señalización de las figuras retóricas, las cuales permiten constatar y sustentar las diversas interpretaciones que se le podría dar a un poema.

\section{Análisis e interpretación}

Es momento de poner a prueba las categorias que le dan base a la interpretación poética para develar los sentidos de los poemas seleccionados. En esta sección, se interpretarán dos poemas pertenecientes a la vanguardia andina para luego compararlos y así poder identificar las similitudes y diferencias de ambos discursos poéticos.

\subsection{Análisis de "balsas matinales", de Alejandro Peralta}

\section{balsas matinales}

Brotan del alvéolo de la mañana

i se echan a templar las cuerdas de las ondas

tensas de alegres barcarolas 
Como un tropel de indios desnudos $\mathrm{p}$ a r t en

abriendo zanjas de silencio

Los estandartes de las velas

Sacuden el polvo del día

El indio balsero Martín

AZOTA EL ESPINAZO DE LAS AGUAS

mientras el sol desde su aeronave

arroja bombas de magnesio

Desde la conchaperla nítida de una nube se desgrana un racimo de gaviotas

son 20 lanchas piratas

que se llevan al pueblo en sus motores

Lejos ha quedado el distrito

i la playa

de bruces sobrelosvientos

La Cecilia

la Juana

la Santusa

Llevan las aguas del corazón entre hondonadas y neveras

i se van por la pampa deshojada

con las órbitas vacías

SE HA IDO LA MAÑANA PRENDIDA DE LAS VELAS 28

\subsubsection{Dispositio o segmentación del poema}

El poema "balsas matinales" se divide en cuatro segmentos. El primer segmento corresponde desde el verso 1 al verso 8 (la partida de las balsas comienza en el amanecer). El segundo 
segmento va desde el verso 9 al verso 14 (la descripción del paisaje lacustre). El tercer segmento va desde el verso 15 al verso 17 (los habitantes del Ande se transportan en las balsas). E1 cuarto segmento va desde el verso 18 al verso 28 (las balsas desaparecen de la vista con el término de la mañana).

\subsubsection{Elocutio o los campos figurativos}

En el primer segmento, en el verso "Brotan del alvéolo de la mañana" (v. 1), se evidencia el campo figurativo de la metáfora que se refiere a la eclosión del amanecer. Por otra parte, en los versos "i se echan a templar las cuerdas de las ondas/tensas de alegres barcarolas" (v. 2-3), se presenta la figura de la personificación que alude al desplazamiento de las balsas sobre las olas del lago Titicaca, lo cual genera una tensión perceptible entre las balsas y las aguas, esto es, las ondas. Asi, la frase "alegres barcarolas" se refiere a que el sujeto poético celebra el desplazamiento de dichas balsas que parten en el amanecer. Seguidamente, se puede evidenciar la figura del simil en los versos "Como un tropel de indios desnudos/parten/abriendo zanjas de silencio" (v. 4-6) (nuestra negrita) que hace referencia a que las balsas cuando se desplazan por las aguas del lago Titicaca dejan huellas, en el aire, casi imperceptibles que se asemejan a "zanjas". Luego, se visualiza la figura de la personificación en los versos "Los estandartes de las velas / Sacuden el polvo del día (v. 7-8) para aludir a que cuando se alzan las velas el día se encuentra en plenitud. Los estandartes son la parte más vistosa de estas balsas y el espectáculo que ofrecen permite enfocarnos solo en ellas y obviar cualquier elemento desagradable. En este segmento, la voz melódica señala una descripción de la partida de las balsas en el amanecer, las cuales dejan huellas, en las aguas del lago Titicaca, en su desplazamiento, así como también dejan estelas en el aire. Hacia el final del segmento, el sujeto poético resalta la figura de las balsas a través de los estandartes para mostrar que son el culmen de este paisaje matinal. 
En el segundo segmento, se evidencia el campo figurativo de la metáfora en los versos "El indio balsero Martín / AZOTA EL ESPINAZO DE LAS AGUAS" (v. 9-10) para aludir a que el indio balsero conduce la balsa y colisiona con la cresta de las olas del lago Titicaca, la cual se asemeja a un "espinazo". Luego, en los versos "mientras el sol desde su aeronave / arroja bombas de magnesio" (v. 11-12) se evidencia la figura de la personificación que alude al desplazamiento del sol durante el día. La exposición de los rayos del sol produce la asimilación de magnesio en los balseros. Además, se presenta el campo figurativo de la metáfora en los versos "Desde la conchaperla nítida de una nube / se desgrana un racimo de gaviotas (v. 13-14) que se refiere a la llegada de las gaviotas en medio de las nubes. El sujeto poético, equipara la forma de una "nube" con la de la "conchaperla" y, de forma paralela, anuncia la presencia de las gaviotas como un fruto desgajado. En este cuadro, la voz melódica describe cómo la naturaleza brinda sustento a los collavinos. Por una parte, le otorga recursos económicos por su trabajo como balseros y; por otro lado, le brinda nutrientes como el magnesio, producto de la exposición al sol, sin mediar ningún esfuerzo. Según la cosmovisión andina, el mundo se divide en tres estratos: el $\mathrm{Ha}$ nan Pacha (mundo de arriba, celestial o supraterrenal), el Kay Pacha (mundo del presente y de aquí) y el Uku Pacha (mundo de abajo o de los muertos). En el poema, esta interpretación postula que el sujeto poético equipara elementos del Kay Pacha como la "conchaperla" y el "racimo" con elementos del Hanan Pacha como la "nube" y las "gaviotas" con el objeto de mostrar la comunicación entre dos mundos, asî como también su complementariedad.

En el tercer segmento, se presenta el campo figurativo de la metáfora en los versos "En pleno lago / son 20 lanchas piratas" (v. 15-16) para aludir a que las 20 balsas son tan rápidas y temerarias como "lanchas piratas". Luego, en el verso "que se llevan al pueblo en sus motores" (v. 17), se evidencia la figura de la hipérbole, esto es, la exageración para indicar que los ha- 
bitantes del Ande se transportan en balsas sumamente veloces. Lo natural, representado a través de la figura del "lago", como lo artificial, representado mediante la figura de las "lanchas", forman parte del paisaje que el sujeto poético quiere mostrar. En este segmento, se evidencia un culto distintivo de la vanguardia hacia elementos tecnológicos como los "motores". Dichos elementos ya se han arraigado en el pueblo ejemplificando con ello que no existe un antagonismo entre la cultura tradicional con la modernidad.

En el cuarto segmento, se evidencia la figura de la personificación en los versos "Lejos ha quedado el distrito / i la playa / de bruces sobre los vientos" (v. 18-20) que alude a la disposición del paisaje de la playa frente al viento. También, se alude a la partida de la lancha y su distancia frente al punto de partida. Seguidamente, se presenta el campo figurativo de la metáfora en los versos "la Cecilia / la Juana / la Santusa / Llevan las aguas del corazón” (v. 21-24) que hace alusión a que la Cecilia, la Juana y la Santusa, mujeres del mundo andino, se despiden con tristeza de los personajes masculinos que viajan en las balsas para retomar sus actividades cotidianas. En el verso "entre hondonadas y neveras (v. 25) se evidencia el campo figurativo de la sinécdoque, la parte por el todo, que se refiere a un cuadro paisajístico compuesto por "hondonadas" y "neveras". En los versos "i se van por la pampa deshojada / con las órbitas vacías" (v. 26-27) se presenta el campo figurativo de la metáfora que alude a la melancolía que sienten los personajes femeninos respecto a la partida de los balseros del lago Titicaca. La pampa transmite el sentimiento de desolación en los personajes generando desconcierto en ellos a través de las "órbitas vacías". En el verso final "SE HA IDO LA MAÑANA PRENDIDA DE LAS VELAS” (v. 28), se presenta el campo figurativo de la metáfora para referirse a la desolación imperante en la pampa, ya que lo más vistoso de la mañana no está en esta, sino se encuentra en las velas de las balsas. En este segmento, se hace referencia a la división de actividades cotidianas entre hombres y mujeres, 
así como la división de los espacios en las que estas se realizan. La pampa es el espacio designado a las mujeres, mientras que el lago es el ámbito adjudicado a los hombres.

En el poema, se evidencia que las balsas, elementos representativos de las actividades cotidianas, ocupan un lugar preponderante en el paisaje andino. Por otra parte, se presenta una comunicación continua entre los elementos del paisaje: la "conchaperla" / las "nubes" y el "racimo" / las "gaviotas", lo cual brinda una idea de unidad. Los elementos modernos no son antagónicos de los vernaculares. De tal modo, se observa la relación entre el Hanan Pacha (mundo celeste) y Kay Pacha (mundo terrenal). También, se evidencia la segmentación de las actividades cotidianas por género: los hombres realizan sus actividades cotidianas en el lago, mientras que las mujeres efectúan sus actividades cotidianas en la pampa. Finalmente, el poema muestra que las características del paisaje andino, por ejemplo, la desolación de las pampas influye en la subjetividad de los personajes collavinos cuando las mujeres se despiden de los balseros. Así, la desolación impera en las pampas con las mujeres, mientras que la alegría se encuentra en las balsas con los hombres.

\subsubsection{Interlectio o los interlocutores}

En el poema "balsas matinales", el locutor no personaje se dirige a un alocutario no representado. Busca reivindicar la importancia de las actividades cotidianas del hombre andino como la navegación a través de los caballitos de totora.

\subsubsection{Inventio o la visión del mundo}

La tematización del poema incide en la importancia del lago y la comparación entre la acción sobre la tierra de labranza y las actividades sobre las aguas lacustres. El primer verso ubica una acción espontánea y natural: "brotar", que indica este surgimiento parecido a las plantas que sobresalen de la tierra. Asi- 
mismo, señala las actividades de los seres humanos con ayuda de instrumentos concretos, las balsas, sobre el lago. Además, la ubicación temporal, que determina una acción que inicia tanto la enunciación del poema como de las acciones de las presencias del poema.

Las relaciones que se establecen, nuevamente, remiten a una compleja actividad entre el ser humano y su entorno. Ahora, pareciese que las acciones de las barcas fueran las que movilizan su espacio de desarrollo, de ahí que se mencione que son "las velas" las que "sacuden el polvo del dia". Ahí donde podría observarse la petrificación y la acumulación del polvo, las "balsas" intervienen con sus actividades. Y más adelante, incluso, precisa más estas relaciones al advertir que "El indio balsero Martín / AZOTA EL ESPINAZO DE LAS AGUAS”. El personaje y su herramienta, la balsa, actúan por medio de actividades de transformación y casi violentas. Y a su vez, los elementos aéreos participan del cuadro como acompañamientos naturales figurados a través de imágenes de la cultura (la aeronave) o de una naturaleza distinta (la conchaperla).

En el poema, por otra parte, se puede observar la separación parcial entre la presencia humana y la presencia lacustre. El locutor remarca una distancia entre ambos espacios; no obstante, también señala que los balseros "se llevan al pueblo en sus motores". De ese modo, puede observarse un tenue nexo entre las esferas de la convivencia humana, en la aldea, y la actividad laboral y natural, en el lago. Las confluencias entre lo cultural y lo natural remarcan una continuidad de convivencia a pesar de la tensión sugerida a partir de las actividades de trabajo que desarrollan los personajes destacados en el poema. Su presencia se constituye como intermediario que rechaza una visión de imposición sobre el territorio o de simple pasividad que torna parte del paisaje revelado.

Visto así, el espacio configurado en esta ocasión no dibuja limites que contrasten con un interior de plenitud andina. Si bien muchas de las figuras se construyen sobre la base 
de elementos culturales que le son ajenos (aeronave, bombas, piratas, etc.), el centro siempre es el mundo andino. La personificación remite a la vitalidad de la naturaleza, su sensibilidad que se encuentra en tensión con las actividades humanas, aunque sin mostrarse salvaje o violenta. Cabe sostener que el espacio desafía la presencia humana, pero que esta por medio de estrategias logra sobresalir y realizar sus actividades cotidianas de laboriosidad. Así podemos leer el verso final en que la mañana se queda adherida a las velas que emplean los balseros como la compenetración del sujeto andino a su medio a través de una distancia adecuada para no violentar ni ser rendido ante la imponente naturaleza, cuya vitalidad se destaca con insistencia.

\subsection{Análisis de "Yaravi Titicaca", de Emilio Vásquez YARAVÍ TITICACA}

Viento de almíbar que me lavas las pupilas

adéntrate hoy hasta el corazón tasajeado

Báteme al dolor en luchas campales para sacarles brillo a nuestros años mozos

Tú en espirales lavanderos

nosotros en un coloquio de aguas dulces

Aquel día se nubló el espacio

i las golondrinas del alma se fueron

al cielo i a las estrellas hondas

$$
\text { I el cuerpo }
$$

de soleada cuna tornóse en cama despilchada

El roquedo amigo desdobló el silencio

i nos dijo al oído

SOIS LOS NUEVOS AVENTUREROS DE LA VIDA 


\subsubsection{Dispositio o segmentación del poema}

Se ha dividido el poema "Yaraví Titicaca" en cuatro segmentos según el criterio temático. El primer segmento corresponde desde el verso 1 al verso 4 (el sujeto poético invoca al viento que rodea al lago Titicaca que lo consuele). El segundo segmento va desde el verso 5 al verso 6 (la purificación del sujeto lírico). El tercer segmento va desde el verso 7 al verso 11 (el alma y el cuerpo del sujeto poético se renuevan). Finalmente, el cuarto segmento va desde el verso 12 al 14 (la revelación del secreto: la vida es un desafío).

\subsubsection{Elocutio o los campos figurativos}

Es importante la señalización de las figuras retóricas inscritas en el poema, ya que constituyen la articulación del pensamiento poético; esto es, la visión del mundo del poeta. No se trata de un mero cotejo de figuras, sino de la articulación de una tesis expresada en la forma literaria. Las figuras retóricas permiten constatar y sustentar las diversas interpretaciones que se le puede dar a un poema. Fundamentan, en sentido estricto, la orientación que un lector le da al poema.

En tal sentido, se puede señalar que el campo figurativo más resaltante a lo largo del poema es la metáfora. Así, en el primer segmento, se evidencia la metáfora en los versos "Viento de almíbar que me lavas las pupilas / adéntrate hoy hasta el corazón tasajeado" (v.1-2) que alude a que el locutor del poema invoca al viento que rodea al lago Titicaca que lo consuele, pues el corazón de este se encuentra lastimado. Con la metáfora "viento de almíbar" el sujeto lírico indica que desea que el viento dulcifique su amargura, esto es, que lo reanime. Ahora bien, el sujeto lírico no solo busca la comprensión, sino también migrar del estado anímico de aflicción hacia una situación que lo libere de sus pesares. Para lograr esta transición, es menester un escenario de lucha interna dentro del sujeto lírico. Por eso, en los versos "Báteme al dolor en luchas campales/para sa- 
carles brillo a nuestros años mozos" (v. 3-4), mediante el campo figurativo de la metáfora, se hace referencia a que el locutor del poema anhela que el lago Titicaca lo renueve para sacar lo mejor de sí. Al parecer, el sujeto lírico es un "mozo" que ha sufrido una decepción amorosa y, por ello, le pide al lago Titicaca que lo desafie en "luchas campales" con el fin de dejar el estado de congoja en el que se encuentra. Los jóvenes para demostrar su gallardía y valor pelean entre ellos y se desafían constantemente. Del mismo modo, el sujeto lírico reclama este desafío para demostrarse a sí mismo cuán fuerte es ante la adversidad.

En el segundo segmento, a través del campo figurativo de la metáfora en los versos "Tú en espirales lavanderos / nosotros en un coloquio de aguas dulces" (v. 5-6) se observa que la voz lírica se encuentra en un estado de purificación, en el cual el lago Titicaca le otorga tranquilidad cuando atiende sus cuitas amorosas. En el verso 5, el pronombre "tú" alude a que el lago es un agente purificador; sin embargo, en el verso 6, mediante el pronombre "nosotros", el sujeto lírico sostiene que el lago Titicaca no es una entidad pasiva que solo lo escucha, sino que también le brinda consejos que erradican su amargura. Por ello, en el poema, se señala en el verso 1 y en el verso 6, respectivamente, que el viento es de "almíbar" y que las aguas del lago son "dulces". El empleo de los términos "nosotros" y "coloquio" evidencian un giro en la predisposición del sujeto poético hacia el lago. Si bien, en el primer segmento, se presenta el reconocimiento de la majestuosidad del lago Titicaca, el último verso del segundo segmento indica una relación horizontal entre el sujeto lírico y el lago Titicaca, lo cual muestra una mayor compenetración entre ambos.

En el tercer segmento, mediante la imagen metafórica "Aquel día se nubló el espacio" (v. 7), el sujeto poético hace alusión a una adversidad que se avizora. En los versos "i las golondrinas del alma se fueron / al cielo y a las estrellas hondas" (v. 8-10) se visualiza la metáfora que alude a que las esperanzas del alma del sujeto poético, a través del símbolo de la "golondrina", tienen 
cabida en un ámbito superior. En contraste con lo señalado en el primer segmento (v. 1-2), donde se observa al sujeto lírico lamentarse por una desventura, en el tercer segmento, el sujeto poético presenta un cambio de actitud frente a la adversidad, pues sus esperanzas no están puestas en cuestiones terrenales, sino en ámbitos superiores. Lo anterior, manifiesta una renovación del alma del sujeto poético, pero siguiendo el legado de la tradición andina, donde no hay una escisión entre alma y cuerpo, dicha renovación debe ser holística. Por ello, en los versos "I el cuerpo / de soleada cuna tornóse en cama despilchada" (v. 10-11), la voz lírica, a través del campo figurativo de la sinécdoque, esto es, la parte por el todo, señala que su "cuerpo" debe experimentar una transformación.

Luego, en el verso que da inicio al cuarto segmento "El roquedo amigo desdobló el silencio" (v. 12) a través de la figura de la personificación del roquedo que se refiere a que la naturaleza devela un mensaje al sujeto lírico, se evidencia una compenetración entre el alocutario y el locutor del poema, lo cual también se percibe en el segundo segmento señalado líneas arriba. Finalmente, en el cuarto segmento, en los versos "i nos dijo al oído / SOIS LOS NUEVOS AVENTUREROS DE LA VIDA” (v. 1314), el "roquedo" mediante la figura de la personificación revela un secreto, el cual alude a que la vida debe enfrentarse como un desafío. A diferencia del segundo segmento, el vínculo entre la naturaleza y la voz lírica presenta mayor grado de complicidad, debido a que la primera le devela un secreto oculto a esta última, lo cual permite afirmar que, en "Yaraví Titicaca" se expresa un proceso dialéctico, donde, en el primer segmento, el sujeto lírico busca consuelo y desprenderse de su aflicción. Luego, en el segundo segmento, atraviesa una etapa de purificación. Seguidamente, en el tercer segmento, se señala una renovación del sujeto lírico que tiene como punto culminante, en el cuarto segmento, la revelación de que la vida constituye un desafío que debemos encarar. 


\subsubsection{Interlectio o los interlocutores}

En el poema "Yaraví Titicaca", el locutor personaje se dirige a un alocutario representado. Busca señalar la importancia del lago Titicaca en la subjetividad de hombre andino a través de la fusión de elementos cosmopolitas y vernaculares.

\subsubsection{Inventio o la visión del mundo}

La gran figura metafórica señala con claridad el espacio asociado a los elementos naturales, entre los que destaca el lago, cuya centralidad queda asumida desde el título. Esta vez se configura una extensión ilimitada de lo que rodea a los actores andinos, que suponen son los que participan en sus encuentros con el viento, el lago y la roca. Esta falta de límites se expresa casi a la mitad del poema en tanto que "las golondrinas del alma se fueron / al cielo i a las estrellas hondas". Esta conexión permite establecer una intención cósmica que se cimenta en la interdependencia con la naturaleza.

Los elementos naturales que son representados manifiestan, como ya advertimos en un apartado anterior, una afectación constante respecto de la subjetividad del locutor. Así, se observa desde el primer verso una dirección de lo exterior a lo interior; se tiene fe en que el viento es capaz, con su propiedad edulcorada, de penetrar por la vista e introducirse hasta lo más intimo, el corazón, para curarlo. Las capacidades de este viento son el de purificar y sanar. En ese sentido, hay una entrega absoluta para la redención en el espacio de la naturaleza.

De igual modo se presenta en los siguientes versos, en los que el locutor se manifiesta de manera colectiva, con lo que subraya una experiencia global y no solo personal. Esta vez con más precisión pareciese que se dirigiera al lago, cuya participación con el personaje colectivizado también remite a una purificación por medio del verbo "lavar". Mientras se asume este carácter del lago, los participantes se asocian por medio del "coloquio" que absorbe las características interiores del "Titi- 
kaka", pues se indica una conversación de "aguas dulces". Esta última característica es importante porque también apunta al "almíbar" del viento al inicio del poema.

Un tercer elemento que se configura de esta conexión entre lo humano y la naturaleza es el "roquedo", cuya participación en la significación del poema es comunicar un mensaje que permita la transformación del locutor colectivo. Esta experiencia transmitida constituye una comunicación particular y casi secreta; podría entenderse que solo es apta para aquellos que permiten ser penetrados por las propiedades purificadoras y curativas del viento y el lago. Un elemento singular es el desdoblamiento del "silencio", con lo que se puede establecer que los elementos de la naturaleza están comunicando mensajes que no podemos comprender con facilidad y solo obtenemos un silencio aparente, de ahí que se necesita una revitalizada capacidad dialogante con lo natural.

En conclusión, el espacio se describe a partir de una vitalidad característica que se inscribe en lo más íntimo del ser humano. Así mismo, hay una disolución de fronteras, pues el locutor colectivo presiente una ampliación cósmica hasta alcanzar las estrellas. Los tres elementos que refieren la naturaleza, en este caso, son el viento, el agua (lago) y la piedra (roquedo), cuya mayor significación constituye en la purificación, la revitalización y la comunicación. De ahí que el locutor pueda plantear una transformación real, ya que tiene su base en las tres presencias descritas.

\subsubsection{Análisis comparativo de "balsas matinales" frente a "Yaravi Titicaca"}

1. En "balsas matinales", se reivindican las actividades cotidianas del hombre collavino, las cuales forman parte de la configuración del paisaje andino. En "balsas matinales", el sujeto poético se sirve del campo figurativo de la personificación para hacer hincapié en que las balsas de totorales ocupan un lugar 
preponderante en el sustento económico del hombre andino. En este poema, se evidencia la división de las actividades cotidianas según el género: los hombres realizan sus actividades cotidianas en el lago, mientras que las mujeres efectúan sus actividades diarias en la pampa.

2. En "balsas matinales", el locutor es no personaje y el alocutario es no representado, mientras que en "Yaraví Titicaca", el locutor es personaje y el alocutario es representado. En ambos poemas se representa el paisaje andino en espacios abiertos.

3. En "balsas matinales", la voz poética señala la influencia que causa la pampa en la subjetividad del hombre collavino. La pampa y el lago transmiten el sentimiento de desolación y alegría, respectivamente, generando desconcierto en los personajes femeninos, la Cecilia, la Juana, la Santusa, y vitalidad en los personajes masculinos, los balseros. Así, la desolación impera en la pampa con los personajes femeninos, mientras que la alegría predomina en el lago con los personajes masculinos.

4. Por otra parte, en "Yaraví Titicaca", la voz lírica se sirve del campo figurativo de la metáfora para señalar la influencia que causa el lago Titicaca en su estado anímico. Ahora bien, el sujeto lírico busca migrar del estado anímico de aflicción hacia una situación que lo libere de sus pesares. Para lograr esta transición, es menester un escenario de lucha interna dentro del sujeto lírico. La voz lírica se encuentra en un estado de purificación, en el cual el lago Titicaca le otorga tranquilidad cuando atiende su aflicción amorosa. El lago Titicaca es una entidad activa que brinda consejos que erradican la amargura de la voz lírica. Si bien, en el inicio del poema, se presenta el reconocimiento de la majestuosidad del lago Titicaca, luego se indica una relación horizontal entre el sujeto lírico y el lago Titicaca, lo cual muestra una mayor compenetración entre ambos. Seguidamente, el sujeto poético presenta un cambio de actitud frente a la adversidad, pues sus esperanzas no están puestas en cuestiones terrenales, sino en ámbitos superiores. Lo an- 
terior, manifiesta una renovación del alma del sujeto poético. Finalmente, el lago Titicaca da cuenta de un secreto al sujeto poético: la vida es un desafío que debemos encarar.

\section{Conclusiones}

- La naturaleza en Peralta se destaca como una presencia viva que genera ciertas resistencias ante la presencia de lo humano. Este participa de una manera constante y logra articularse con su medio para elaborar su sustento. Esto, en el plano de las figuras, puede revelarse en las metáforas que buscan conectar universos de sentido bastante disociados. En Vásquez, lo natural se interrelaciona intimamente y de modo armónico con lo humano. Pueden ser, por un lado, continuaciones entre la corporalidad humana y la materialidad de la naturaleza y, por el otro, en la actuación de esta última sobre la primera para que se convierta en figura activa y plena.

- Los espacios de ambos autores no prefiguran una limitación territorial cerrada. Por tanto, se puede sostener que, sugerentemente, existe una apertura de la cultura andina a lo foráneo. Esto en función de las construcciones figurativas que constantemente aluden a elementos de otros conjuntos culturales.

- En los dos autores revisados, el agua (lago), la piedra (roquedo y peñasco), la vegetación (pasto y pastaje), entre otros, son los elementos que configuran los espacios andinos. Pero no son solo objetos para el beneficio humano, sino que participan junto al locutor para otorgarle un sentido en el mundo en el que se instala.

- En ambos escritores, de modo particular, el lago es una presencia muy fuerte, pues otorga características peculiares a los actores o permite sus actividades en los trabajos. Su naturaleza es viva y vivificante. No solo es agua acumulada, sino, en Peralta, un centro de actuación jerárquica o de re- 
lación laboral y, en Vásquez, una función purificadora del cuerpo y lugar para la captación del sustento.

- Los poemarios contienen una serie de grabados que pretenden enmarcar lo manifestado por los poemas. En ambos, los paisajes serían solo elementos referenciales si no fuera que por medio de los discursos líricos se identifican esas propiedades de naturaleza viva y vivificante.

\section{Referencias bibliográficas}

Albaladejo, T. (1991). Retórica. Madrid: Síntesis.

Arduini, S. (2000). Prolegómenos a una teoría general de las figuras. Murcia: Universidad de Murcia. Servicio de publicaciones.

Arias-Larreta, A. (1951). La naturaleza y su expresión en la literatura peruana. Revista Iberoamericana, XVI (32), 1-60.

Arrieta, D. (2007). Alejandro Peralta, Ande, por Dimas Arrieta. La alforja de Chuque. Coloquio Internacional Des-encuentros: las vanguardias, México y Perú. https://bit.ly/38JAKa4

Asensi, M. (2010). La oveja perdida y la emancipación de la literatura comparada. En Morales Mena, Javier (comp.). La trama teórica/Escritos de teoría literaria y literatura comparada. Lima: Fondo editorial U.N.M.S.M.

Kopf, M. (2011). Andinismo, paisaje andino, espacio mágico-mítico y cerros vivientes: los Andes en la obra de Arguedas. Alemania: Johannes Gutenberg-Universität Mainz, Pueblo cont, 22 (1), 103-109

Lauer, M. (2001). Antología de la poesía vanguardista peruana. Lima: El Virrey.

Palau, G. (1980). La poesía indigenista de vanguardia de Alejandro Peralta. Revista Iberoamericana, xxLvi (111), 205-216.

Peralta, A. (1926). Ande. Puno: Titikaka.

Terbullino, V. (2011). La imposible articulación de las tradiciones hispanista e indigenista en la imagen de la mujer en Ande de Alejandro Peralta. Tesis para optar el Título de Licenciado en 
lingüística y Literatura con mención en Literatura Hispánica. Lima: Pontificia Universidad Católica del Perú.

Steiner, G. (1978-1992). ¿Qué es la literatura comparada? Pasión intacta/Ensayos, Madrid: Siruela.

Vásquez, E. (1933). Altipampa. Puno: Edit. Titikaka. 